\title{
A Comparative Study of Interpersonal Function Political Speeches-A Case Study of Inaugural Speeches by Theresa May and David Cameron
}

\author{
Zhaodong Zeng \\ Shanxi Normal University, Linfen, China \\ Jianhua Wang \\ Renmin University of China, China
}

\begin{abstract}
This paper, on the basis of the interpersonal function of systemic functional grammar, aims to analyze interpersonal meanings construction in the inaugural speeches of Theresa May and David Cameron in terms of personal pronoun, mood and modality. It is identified that similarities and differences are reflected in the construction of interpersonal meanings. In light of similarities, both of them take the advantage of first person as a way that conveys their wills and builds up their authorities, seek to shorten interpersonal distance with the use of modal verbs of median and low degree, and employ the indicative mood to express their views and win supporters. On the other hand, they show different tendencies towards the use of modal verbs of high degree of modality and choices of second person verbs with regard to their distinct inaugural backgrounds. A comparative study of different inaugural speeches from the perspective of systemic functional grammar will help to gain an in-depth understanding of the organization and informational purposes of political speeches.
\end{abstract}

Index Terms - inaugural speeches, interpersonal function, comparative study

\section{INTRODUCTION}

Systemic Functional Grammar (SFG) is founded by the English linguist M. A. K. Halliday, aiming to expound the internal relations in language as a system network and revealing that language serves as an approach to social interaction by regarding actual uses of language as the object of study (Hu Zhuanglin, 2011). In the system of Halliday's functional grammar, an essential part of SFG, language has three meta-functions which are used as the basis for exploring how meanings are created and understood. These meta-functions refer to ideational function, interpersonal function and textual function (Halliday, 2008). Among them, the interpersonal function is defined as " an interactive event involving speaker, or writer, and audience" (Halliday, 2008, p.106). In other words, language plays a role of building and maintaining appropriate social relations, and indicates the roles of the participants in communication. And " it is also a proposition, or a proposal, whereby we inform or question, give an order or make an offer, and express our appraisal of and attitude towards whoever we are addressing and what we are talking about " (Halliday, 2008, p.29). On the whole, the interpersonal function works to represent the speaker's identity and status and show his or her attitudes, motivations or inference to the surroundings. According to Halliday's theory, the interpersonal function of language can be realized lexico-grammatically by mood type, modal operator and vocative address, which are particular elements of the clause. The choice of vocative address plays an essential role in the establishment and maintaining of the relationship between the speaker and the listener. Mood shows what role the speaker selects in the speech situation and what role he or she assigns to the addressee. Modality is related to speakers' judgement and will, expressing the effectiveness of proposition that the speaker makes judgement about, obligations of the listener that the speaker asks to fulfill or personal will of proposing.

Political oration is to elaborate speakers' standpoints, opinions, attitudes and proposal with the aim at one country's internal affairs and diplomacy. There are many types of political speeches, including the campaign speech of the head of the government, policy speech, inaugural speech and more (Li Yuanshou, Zhou Kunshan, 2003). This kind of speech aims to help the speaker obtain voters' support and advocacy. For this goal, orators have to decide how they give their speeches and what they choose to say in their speeches tactfully and subtly. On the one hand, the speeches serve well to express accurately their political views and attitudes to the audience and on the other hand, the speeches assist speakers in building harmonious relationship with the audience to gain their support. Therefore, according to the view of functional linguistics ---- choice is meaning, the interaction between the speaker and the audience in political speeches reflects interpersonal function. As all types of political speeches have a lot in common in some aspects, such as their natures and purposes, their similarities are obviously prominent in the construction of interpersonal meaning. It cannot be denied that individuality does exist objectively, which is true of speeches of the same type.

Based on the system of Halliday's theory of interpersonal function, this paper selects the inaugural speeches of 
newly-appointed British prime minister Theresa May and ex-prime minister Cameron as linguistic data to analyze and compare. This paper seeks to reveal differences and similarities of their speeches in the construction of textual interpersonal meaning from the perspective of mood type, modal operator and vocative address as well as to analyze the reasons why they choose different strategies. In so doing, this paper aims to look into the potential meanings and intentions of political speeches.

\section{THE OVERVIEW OF INTERPERSONAL FUNCTION IN SYSTEMIC FUNCTIONAL GRAMMAR}

\section{A. Vocative Address}

Vocatives are usually the terms used to address others. In many dialogic contexts, the speaker uses them to mark the interpersonal relationship, and sometimes claim superior status or power (Halliday, 2008). In texts, using vocative address properly imposes positive influence on the establishment and maintaining of the interpersonal relationship between the speaker and the listener. Li Zhanzi (2002) argued that vocative address was also able to serve the function of interpersonal meaning of language apart from mood type and modal operator. In English language, personal pronouns are divided into three types: first person, second person and third person, and each personal pronoun has singular and plural forms. People always refer to the speaker in communications as the first person, the listener as second person and others not present as the third person. This version of explanation is not accurate and complete as it stands simply from the perspective of social interaction and without taking enough factors into consideration. Different circumstances, different users and scopes of demonstrative pronouns all have influence on what and who are referred to. As the meanings of personal pronouns are complex and dynamic, all pronouns need to be analyzed case by case. In total, first person and second person in speeches are employed more frequently due to their function of the construction of interpersonal meaning in texts. Compared to third person which gives people the feeling of distance, the abundant use of first person and second person in texts has the advantage of shortening the distance between the speaker and the listener. Then it can help succeed in delivering the audience feelings of harmony and kindness and pushing communicators to interact more closely so as to reach the goal of communication.

\section{B. Modality}

Modality, a major component in Systemic Functional Grammar, serves to realize interpersonal function and involves degrees and scales. Halliday (2008) established three basic values to formalize the modal judgment " high, median and low" (p.620). There are many forms to show modality in texts. For example, modality can be realized with modal verbs such as " can, will, must", with modal adverbs such as " probably, certainly" and with predicate verbs such as " be supposed to, be obliged to". This paper focuses on the application of modal verbs to the construction of interpersonal function. As the meaning modality expresses lies between "YES" and "NO ", namely " positive " and " negative ", modality thus has scales. The scales can make what is said inclined to be positive or negative and also express possibilities, frequency, obligation and will of different degrees. The scales of modality are divided into three degrees: low, median, high (see table 1.)

TABLE 1

VALUES OF MODAL VERBS

\begin{tabular}{|c|c|c|}
\hline & \multicolumn{2}{|c|}{ Positive } \\
\hline low & Can, may, could, might, dare & Neegative \\
\hline median & Will, would, should, shall,is/was to & Won't, wouldn't, shouldn't, isn't/wasn't to, shall not, will not \\
\hline high & Must, ought to, need, have/had to & Mustn't, oughtn't to, couldn't, mightn't/may not, hasn't/hadn't to \\
\hline
\end{tabular}

\section{Mood}

Systemic Functional Grammar believes that in the course of speech, the speaker himself or herself is considered to play a specific role and to assign a specific role to the listener (Halliday, 1973). In Halliday's words, mood shows what role the speaker selects in the speech situation and what role he or she assigns to the addressee. There are just two basic tasks they need to complete regardless of how information roles alter: giving or demanding, and service, commodity or messages are exchanged in communication. The roles and the things in the exchange, two major factors involved when language is used as a communication tool, jointly perform four linguistic functions: offer, statement, command and question. In terms of grammatical structure, among these four functions, statement, command and question are respectively realized by declarative mood, interrogative mood and imperative mood. Command, unlike them, can be realized by different moods. Halliday (2000) defined mood structure as " Subject + Finite ". Subject, as an important part in proposition, is responsible for effectiveness and success of proposition or proposal. On the other hand, " finite ", a reference point for proposition, connects the proposition with the contexts where social interaction takes place. "Finite" offers two reference points in English language. The first one is the time when speech happens, such as "was " in "An old man was crossing the road", and the other one is the judgement the speaker makes, such as " can't" in "It can' t be true " (Hu Zhuanglin, 2005). The former one is called primary tense and the latter modality. Mood is the core of communication as mood is the key to the exchange of clauses (Thompson, Geoffrey, 1996). The relationship between positions of subject and finite decides the mood : if the subject is followed by finite, this clause belongs to 
declarative mood; if the subject is after the finite, this clause interrogative mood; if there is neither subject nor finite, this clause imperative mood (Hu Zhuanglin, 2005).

\section{COMPARISON OF THERESA MAY's INAUGURAL SPEECH WITH CAMERON'S}

How politicians make speeches and what they choose to say are generally influenced by specific time, aims and social backgrounds (Sun Aizhen, Zhao Jiangrong, 2014). This paper chooses two inaugural speeches as linguistic data, one made by Cameron after he won the general election in May of 2010 and the other one made by Theresa May who was the newly appointed prime minister in July of 2016. On the one hand, two events both happened in Britain: Britain fell out of the EU and new prime minister was appointed. Therefore, it is important and meaningful to study the inaugural speeches new prime minister has made. On the other hand, to analyze and compare inaugural speeches of the same kind from the perspective of interpersonal function can not only help to explore the differences and the similarities of the construction of interpersonal meaning between speeches of the same kind, but also to deepen the understanding of the interpersonal function in contexts.

In May of 2010, the Conservative Party Cameron belonged to won in the general election and then became the biggest party in the parliament. However, the Conservative Party and the Liberal Democrats were jointly combined into coalition government through negotiation because of failure to obtain multitude seats in parliament. Cameron was appointed as the prime minister and also became the youngest prime minister ever since 200 years ago. As then Britain just got over financial crisis, major issues remained to be addressed, including slow economic recovery, financial deficit and people's disappointment about the administration. It was a top priority to find a way out to convince people to believe that coalition government was willing and able to solve all the problems the country was confronted with as well as to reestablish people's trust in politics and motivate them to make joint efforts for a more responsive society.

Theresa May, the newly appointed prime minister, unlike Cameron who won the general election by touching people with the voice of " reform ", went through another turning point, Brexit. In her inaugural speech, Theresa May, to begin with, recognized ex-minister Cameron's great contribution to the legalization of same-sex marriage and the policy in exemption from individual income tax for low income earners. She would remain committed to Cameron's idea of " one country" and renew the concept of " unity". In addition, she also made a promise that she would devote herself to each and every citizen and call for all citizens' joint efforts to cope with Brexit for a better England. As a female prime minister, who was entrusted with a mission at a critical and hard point, she had to figure out how to give an inaugural speech to quickly gain people's trust and how to make people aware that all citizens must make concerted efforts to get through the hard time of reform.

\section{A. Interpersonal Function by Vocative Address}

Vocatives usually serve as an important pragmatic strategy to construct identity that aims to achieve interpersonal meaning and communication effect. It is common that vocatives function as subject in political speeches. According to the statistics ( see table 2 ), Cameron and Theresa May in their own inaugural speeches employ a lot of personal pronouns as subject. The times of use of first person, second person and third person in Cameron's inaugural speech are respectively 56, 1, 4, accounting for $91.8 \%, 1.6 \%, 6.6 \%$; those in Theresa May's inaugural speech are respectively 41 , 39,1 , accounting for $50.6 \%, 48.2 \%, 1.2 \%$. It can be seen that although both of two ministers are inclined to use first person there is still difference in the use of them, which is mainly reflected in the comparison between the use of first person and second person. The frequency of the use of first person and that of second person in Cameron's inaugural speech differ greatly. In contrast, Theresa May seems to strive to find a balance between them. We will discuss and analyze them in the following part.

TABLE 2

Times AND PERCENTAGE OF PERSONAL PRONOUNS IN TwO SPEECHES

\begin{tabular}{|c|c|c|c|c|c|c|}
\hline $\begin{array}{c}\text { orator } \\
\text { Times, percent } \\
\text { person }\end{array}$ & \multicolumn{2}{|c|}{ First person } & \multicolumn{2}{|c|}{ Second person } & \multicolumn{2}{|c|}{ Third person } \\
\hline Cameron & 56 & $91.80 \%$ & 1 & $1.60 \%$ & 4 & $6.60 \%$ \\
\hline Theresa May & 41 & $50.60 \%$ & 39 & $48.20 \%$ & 1 & $1.20 \%$ \\
\hline
\end{tabular}

Two kinds of first personal pronouns are used in the inaugural speech of Cameron: we and I. It is certain that " I " refers to himself while it is complex to tell who "we " refers to. It is generally believed that the personal pronoun "we " reflects two meanings, inclusive and exclusive, which are both shown in Cameron's speech. Inclusive "we " of 9 times semantically refers to all the British people including Cameron himself, and exclusive "we " of 5 times refers to the new coalition government composed of the Conservative Party which he belongs to and Liberal Democrats led by Nick Clegg. In his inaugural speech, Cameron tactfully uses inclusive and exclusive " we " in a mixed way. He sometimes stands at the same line with British people to face the problems and sometimes makes promises that he will protect public interests in honor of coalition government. He sometimes calls for the confidence and trust in the reestablishment of Britain, and sometimes sincerely appeals for the building of a more responsible social community. 
All he says and does in his inaugural speech successfully shapes himself a people-caring, responsive and competent image. Two examples are shown below.

1. And a guide for that society, that those who can, should, and those who can't, we will always help. I want to make sure that my government always looks after the elderly, he frail, the poorest in our country. We must take everyone through with us on some of the difficult decisions that we have ahead.

2. That means fighting against the burning injustice - that if you're born poor, you will die on average nine yeas earlier than others. If you're black, you are treated more harshly by the criminal justice system than if you're white...

In the example 1, the first two "we "s are exclusive, referring to the coalition government led by Cameron, and the third "we" is inclusive, referring to all the British people and all the members in his coalition government. Inclusive "we", on the one hand, conveys the message that the coalition government represented by him stands at the same line with all British people. By doing so Cameron succeeds in shortening the distance between people and government and then thereby in building a relationship of mutual trust. On the other hand, exclusive "we " plays a key role in making the coalition government more authoritative and shaping a mighty image of government. Both the synergy of inclusive and exclusive "we "s help Cameron not only win people's trust and favor but also effectively and powerfully appeal to people to join hands for a more responsible society.

"We "s in Theresa May's inaugural speech are to be not discussed as all the "we "s in her speech shows the same aim as Cameron's speech. The second personal pronoun " you " generally refers to the audience. In Theresa May's inaugural speech, " you " refers to each British citizen and particularly those who are struggling for life and suffering from social inequity. Li Zhanzi (2001) argued that addressing the audience directly triggers oral communication model so as to make the existence of audience more obvious. Han Kaihua (2012) pointed that modal words, modal operator and the repetition of personal pronouns makes texts more powerful and persuasive. In example 2, the sentence model " if you are... you will/ are..." is repeated, in which the ordinary people that "you "s refer to are put in a prominent position. This has the advantage of making the speaker and the audience feel like they are talking face to face, thereby triggering their emotional resonance more easily. By doing so, the speaker can naturally gain people's attention, make them realize that they are closely bound up, and instantly shorten the distance between the government and citizens. Thus it can be seen that second personal pronoun "you" is an intentional choice she has made against the political background at that point. All in all, in light of the construction of interpersonal function of personal pronoun, both of these two speeches ultimately have reached the same goals in spite of their different ways.

\section{B. Interpersonal Function in Modal Choice}

There are ways to realize modality in texts. Various expression ways of modality can cause prominence of quality or quantity, which is the key to the comprehension of text genre and interpersonal meaning (Cao Xia, Sun Qiyao, 2014). Values of high, median and low, to different degree, are shown in inaugural speeches of Cameron and Theresa May. Firstly, in the statistical table of the use of modal verbs in two speeches ( see table 3), it is found that Cameron uses modal verbs in total as almost frequently as Theresa May, respectively 19 times and 18 times, but there is difference in ways of performing. On the one hand, Modal verbs of median value account for most in both, while there is no great difference among the use of modal verbs of high, median and low value in terms of values. In contrast, Theresa May is inclined to use modal verbs of median and low value without using modal verbs of high value at all. On the other hand, types of modal verbs in Cameron speech are more diversified, including " must, can't, need, will, should, would and can ", while Theresa May uses only three types of modal verbs, " will, will not, can ".

The difference shown above has something to do with the difference of speeches' backgrounds, aims and strategies to construct interpersonal meaning. Cameron winning the election is the result of people' election. He needs to make use of multitude of modal verbs of median and low value to maintain a harmonious relationship with citizens. In addition, as a prime minister, the symbol of authority and power, he has to use plenty of modal verbs of high value in order to be well recognized and supported by common people. The situation of Theresa May is more complex as she is appointed as the prime minister when Cameron announces his resignation after Brexit referendum. British voters know a little about her although Theresa May remains a member of Conservative Party for four generations, and thus it is highly significant for her to figure out how to build relations with citizens and gain their trust and support. That is the reason why she tries to avoid using modal verbs of high value which highlight power relationship. Her tendency to use modal verbs of median and low value more often helps shorten the distance between her and the audience. Two examples are shown below.

TABLE 3

COMPARISON IN TIMES AND PERCENTAGE OF THE USE OF MODAL VERBS

\begin{tabular}{|c|c|c|c|c|}
\hline \multirow{2}{*}{ Values } & \multicolumn{2}{|c|}{ Cameron } & \multicolumn{2}{c|}{ Theresa May } \\
\cline { 2 - 5 } & Times & Percent & Times & $17 \%$ \\
\hline Low & 6 & $32 \%$ & 3 & $83 \%$ \\
\hline Median & 8 & $42 \%$ & 15 & $0 \%$ \\
\hline High & 5 & $26 \%$ & 0 & 0 \\
\hline
\end{tabular}

3. We will do everything we can to give you more control over yourlives. When we take the big calls we will think not of the powerful, but you. When we pass the new laws we will listen not to the mighty, but you. When it comes to taxes we will 
prioritize not the wealthy, but you ...(Theresa May)

In example 3, Theresa May makes use of "will, can, will not" of median and low value instead of modal verbs of high value, especially the repetition of "will not... but you" sincerely and firmly reflects her standpoint and views. Her speech is simple and unadorned but makes a strong promise all the ordinary people are most eager to hear. That is she will be in power to represent and protect the interests of ordinary people instead of those who are prominently rich and powerful, which gives people hope and makes her speech and the government widely acknowledged. What is more, it sets a solid basement for the call for joint efforts to shape a new image of the country and build a better country.

4. And a guide for that society, that those who can, should, and those who can't, we will always help. I want to make sure that my government always looks after the elderly, the frail, the poorest in our country. We must take everyone through with us on some of the difficult decisions that we have ahead. (Cameron)

Unlike Theresa May, Cameron takes the strategy of combining modal verbs of high, median and low value to construct interpersonal meaning. First, Cameron expresses his concerns over each British citizen by using "can, should, can't, will " of median and low value. That helps shorten the distance between Cameron and ordinary people and gain their trust and favor. Then Cameron, with the use of " must", firmly expresses his standpoint and his resolve of leading each citizen to go through hard times. This modal verb of high value makes his wish more powerful and persuasive and helps Cameron create a people-caring and mighty image of leader.

\section{Interpersonal Function of Mood Choice}

Both of the two inaugural speeches last about four minutes. In Cameron's speech, there are thirty sentences in total, most of which are declarative sentences expressing indicative mood and offering information. With these statements Cameron expresses his gratitude for the contributions last government has done and points out the mixed situation of deficit and two parties in coalition. At the same time, he shows to people his resolve to rebuild the government and his hope that all citizens can join hands to create a more responsible society.

5. Yes, that's about cleaning up expenses; yes, that's about reforming parliament; and yes, it's about making sure people are in control and that the politicians are always their servants and never their masters.

Cameron demonstrates some measures his administration will take to rebuild people's trust with the use of three declarative sentences: reducing expenditure, parliamentary reform, ensuring people's management and politicians' service for people. The repetition of his mood stresses his resolve to reform and makes the messages of his statements more reliable, which helps to establish a good interpersonal relation with people.

There are 33 sentences in Theresa May's speech in total, most of which are of indicative mood. What is different from Cameron is that the sentence patterns of statements are more diversified. Apart from traditional statements, she also uses IF adverbial clause of condition and temporal adverbial clause and others ( see example 1 ). IF adverbial clause of condition can make people feel care from the government, no matter whether they cannot live long due to poverty or they are treated unfairly because of their black skin. Theresa May government actually sends a message with the repetition of the mood: if you are treated unfairly, we dare not pretend not to know, and instead that is what we must change. Compared to those gaudy promises, this sincere attitude is easier to help her win people's trust and support.

It can be seen that both of their inaugural speeches adopt the same strategy in terms of mood. What needs to be noticed is that statements like " Real change is when everyone pulls together, comes together, works together, when we all exercise our responsibilities to ourselves, to our families, to our communities and to others " ( Cameron ) do not use indicative mood but still achieve the interpersonal function of " giving " and " receiving".

\section{CONCLUSION}

There are many ways to realize the interpersonal function in political speeches. Based on interpersonal function of SFG, this paper discusses the construction of interpersonal function in inaugural speeches of Cameron and Theresa May from the perspective of vocative address, modality and mood. It aims to reveal differences and similarities in the strategies of reaching the goal of speeches as a way that helps understand interpersonal meaning and purposes of inaugural speeches. The research finds that both of the two speeches have something in common and something different.

The similarities lie in that 1) in vocative address they both are good at making use of first person to express their will and build their authority; 2) in modality they utilize tactfully modal verbs of median and low to shorten the distance between them and people so as to successfully establish a sound relation; 3) in mood they take the advantage of employing indicative mood to express their propositions to gain support.

Their difference is mainly reflected in the specific manipulation of vocative address and modality. In modality Cameron tends to employ modal verbs of high value to establish his authority while instead Theresa May tries to avoid using this kind of modal verbs of high value so that she can get people's recognition quickly and lower the risk of being excluded by people. In the choice of vocative address, Cameron seems to show more authority, who mainly makes use of first person "we " and "I". Theresa May instead is more inclined to integrate her authority and friendliness with the use of first person "I " and second person " you ", which not only builds her authority but also shortens the distance between her and voters as well as helps her gain people's trust.

What is worth noticing is that in the construction of interpersonal meaning, the choice of vocative address, modality 
and mood are not independent but complementary to each other.

\section{REFERENCES}

[1] Cao Xia, Sun Qiyao \& Xin Dan. (2014). Studies on personal meaning of responsible modality in political speeches---weekly speeches of Obama as example. Contemporary Foreign Languages Studies, 4, 12-17.

[2] Halliday, M.A.K. (2000). An introduction to functional grammar (2nd ed.). Beijing: Foreign Language Teaching and Research Press.

[3] Halliday, M.A.K. (2008). An introduction to functional grammar. Beijing: Foreign Language Teaching and Research Press.

[4] Halliday, M.A.K. (1973). Explorations in the functions of language. London: Edward Arnold.

[5] Han Kaihua. (2012). Re-explanation of I Have A Dream---from the perspective of theory of modality. Foreign Language Education, 4, 49-52.

[6] Hu Zhuanglin. (2011). Linguistics, a course Book. Beijing: Peking University Press.

[7] Hu Zhuanglin, Zhu Yong \& Zhang Delu, et al. (2005). An introduction to systemic-functional linguistics. Beijing: Peking University Press.

[8] Li Yuanshou \& Zhou Kunshan. (2003). Studies on lecture. Wu Han: Huazhong University of Science and Technology Press.

[9] Li Zhanzi. (2001). Multiple interpersonal meaning of cognition modality in academic speeches. Foreign Language Teaching and Research, 5, 353-358.

[10] Li Zhanzi. (2002). Studies on interpersonal function of speech. Shanghai: Shanghai Foreign Language Education Press.

[11] Ren Yuxin. (2016). Studies on identity construction of personal pronouns in academic speeches. Foreign Language Research, 2 , 23-28.

[12] Sun Aizhen \& Zhao Jiangrong. (2014). Modality calculation of presidents' inaugural speeches. Journal of PLA Foreign Language Institute, 4, 95-102.

[13] Thompson, Geoffrey. (1996). Introducing functional grammar. London: Arnold.

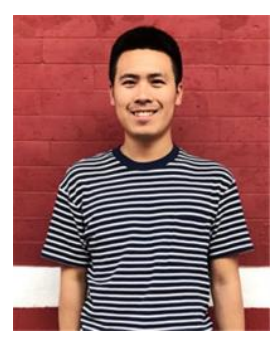

Zhaodong Zeng, was born in Xinzhou, Shanxi province of China in 1995. He received his bachelor degree in English Teaching from Xinzhou Teachers University, China in 2017.

He is currently a graduate in the School of Foreign Languages, Shanxi Normal University, Linfen, China. His research interests include foreign linguistics and applied linguistics.

Jianhua Wang, the corresponding author, is the master supervisor of the first author. He is the professor and PhD supervisor in Renmin University of China. He has published over ten papers in core journals at home and abroad. 